\title{
Metáforas biomédicas e interpretación social: ausencias y emergencias dentro de la esfera pública contemporánea
}

\section{| ${ }^{1}$ Sebastián Medina |}

Resumen: El trabajo problematiza sobre el uso de metáforas biomédicas para interpretar fenómenos del mundo social contemporáneo. A partir de la Teoría Lingüística Cognitiva y la Crítica Postcolonial se analizan las metáforas del "Cuerpo Social” y la "Semántica Inmunitaria" como productos históricos de transformaciones tecnológicas y socio-políticas cuyo carácter es altamente conflictivo. Este tipo de metáforas evocarían una secuencia unilineal de examen/diagnóstico/ terapia social que facilitaría cierto manejo centralizado y racional del poder. Se concluye que ciencias biomédicas, ciencias sociales y esfera pública del Norte Global compartirían una matriz metafórica asociada a una racionalidad moderna (capitalista/colonial/patriarcal) plegada sobre sí misma, que comienza, sin embargo, a ser progresivamente fisurada por "otras metáforas" producidas en el Sur Global.

> Palabras-clave: metáforas biomédicas; epistemologías del Sur; cuerpo social.
${ }^{1}$ Escuela de Salud Pública, Universidad de Chile. Santiago, Chile (sebamedi@gmail.com). ORCID: 0000-0003-4659-680X

Recebido em: 28/06/2017 Aprovado em: 17/03/2018 Revisado em: 15/05/2018 
Massagué presentó este miércoles, en Nueva York, las bases de su trabajo de investigación sobre el cáncer, al que presenta como una entidad de células que no respetan el funcionamiento del resto y se convierten en los "terroristas" del organismo. El científico, galardonado este año con el Premio Príncipe de Asturias de Investigación, explicó esta enfermedad como una sociedad de individuos, en la que las células son parte "esencial de la vida", y "deben renunciar a cierto grado de libertad" para que funcione el sistema. El cáncer es "el fracaso" de esa comunicación, indicó el científico, para agregar que surge cuando las células empiezan a "actuar como delincuentes" y proliferar cuando no deben. Diario Uruguayo El Observador (EFE, 2011)

\section{Introducción}

Este trabajo problematiza una forma de mirar la sociedad y el cuerpo humano. La facilidad de la nota periodística del epígrafe para cruzar dimensiones sociales con biomédicas es elocuente: somos espectadores de un rápido traslado de cierto ideario social directamente hacia el interior de nuestro cuerpo, y no nos llama mayormente la atención. Recuerdo haber visto a la edad de 10 años una serie de animación infantil francesa traducida como Érase una vez el Cuerpo Humano (BARILLÉ, 1987) donde un leucocito, representado por un gordo policía blanco con garrote, golpeaba a una bacteria dibujada como un grotesco personaje verde, manchado, apestado. ${ }^{1}$ Esta imagen marcaba cierta forma de entender el funcionamiento del cuerpo humano que fue difundida a través de varias generaciones (entre los 1980s y 2000s) en nuestros países del Sur Global bajo dictaduras conservadoras. ${ }^{2}$ La idea del leucocito golpeando a la bacteria, sin embargo, poco parece haber cambiado en el curso de los últimos 30 años cuando se la compara con el "terrorismo celular" del epígrafe, revelando una inquietante persistencia de este tipo de narrativas a pesar de los cambios sociales, políticos, tecnológicos y culturales que el mundo han experimentado desde entonces.

Si este tipo de narrativas sigue siendo frecuente dentro de la esfera pública puede pensarse que es por su capacidad para articular y estabilizar diferentes discursos entorno a fenómenos biomédicos y sociales complejos, creando "sentidos comunes" de relativo fácil uso y difusión. ${ }^{3}$ Imaginar que el mundo bajo nuestra piel es fundamentalmente similar al mundo social que cotidianamente nos ofrecen los medios de comunicación masiva facilitaría, en cierta medida, su comprensión. Sin embargo, durante estos traslados también se producirían una naturalización 
de categorías e instituciones sociales, que ganan estabilidad al ser planteadas como realidades biomédicas, del interior de nuestros cuerpos (LOCK, 1993; SCHEPERHUGHES; LOCK, 1987).

En sentido contrario, los traslados semióticos desde la interpretación social a la investigación biológica y médica ya han sido analizados por un buen número autores desde la filosofía, sociología, historia y antropología de las ciencias y de la medicina, las cuales han destacado la frecuente presencia de conceptos y modelos asociados a los discursos socioculturales hegemónicos dentro de las teorías y objetos científicos (ARBIB; HESSE, 1986; CANGUILHEM, 2000; FOUCAULT, 1966; HACKING, 1990; KELLER, 2002; ROSEN, 1985). Estos conceptos inicialmente "foráneos" serían integrados y estabilizados mediante complejos procesos de traslado donde son transformados en sus sentidos primarios, pero continúan transportando ideologías y relaciones de poder tanto en las dimensiones sociales, culturales como de género (BRADIE, 1999; HARAWAY, 1991; LOCK; NGUYEN, 2010; LUPTON, 2010; MARTIN, 1991; REYNOLDS, 2014). ${ }^{4}$

Partiendo de estos referentes, durante este trabajo realizo una revisión de bibliografía seleccionada acerca de la doble direccionalidad e interdependencia de estos traslados semióticos (desde la biomedicina al campo social y viceversa) destacando su importancia epistemológica (NUNES, 2014; SANTOS; MENESES, 2014) y las consecuencias en la realidad de sus producciones, es decir, a la política ontológica que generan (MOL, 1999, 2002). Para ello construyo una interpretación que comienza articulándose a la Teoría Lingüística Cognitiva (LAKOFF; JOHNSON, 1980) y deriva finalmente hacia los denominados "Estudios Postcoloniales de la Ciencia y la Tecnología" (HARDING, 2011).

Inspirando en las críticas epistemológicas de Boaventura de Sousa Santos (1987, 1991, 2000) y el uso estratégico que ha dado a las metáforas dentro de sus investigaciones, ${ }^{5}$ el trabajo partió de tres presupuestos, a saber:

1) que los traslados de sentidos desde un tipo singular de comprensión sobre la sociedad y la cultura - como la existencia de cierta división del trabajo y la defensa armada de fronteras nacionales, evidentes dentro del ejemplo de la serie animada "Erase una vez el Cuerpo Humano" que ya mencioné - hacia el mundo de la biomedicina son esencialmente metáforas, es decir, artefactos lingüístico-conceptuales que ex profeso generan una relación entre dos entidades inicialmente distintas que, mediante este movimiento, contaminan y fusionan 
parte de sus cualidades, generando nuevos sentidos y posibilitando la observación de propiedades y vínculos antes inexistentes;

2) que estas metáforas no se producen por el azar, ni tampoco se activan solamente en contextos didácticos, sino que serían recursos epistemológicos importantes dentro de la ciencia moderna, y por lo tanto estarán atravesadas por las dinámicas histórico-sociales del saber/poder, y además;

3) que serían una forma efectiva de naturalizar comportamientos, normas e instituciones delimitadas socio-culturalmente que, mediante su objetivación y estabilización en categorías "naturales y universales" como las biomédicas, pasan a formar parte de ciertos discursos del sentido común de la globalización neoliberal, es decir, se convierten en poderosos localismos globalizados. ${ }^{6}$

Guiado por la pregunta inicial ¿por qué las metáforas biomédicas persisten dentro de los discursos de la esfera pública en la globalización neoliberal? desarrollo, a continuación, cuatro secciones secuenciales. En la primera, destaco algunos elementos básicos de la Teoría Lingüística Cognitiva sobre las metáforas en función destacar su importancia dentro de la experiencia cotidiana del mundo y su relación con el poder. En la segunda y tercera secciones, analizo desde literatura seleccionada dos ejemplos de metáforas biomédicas persistentes dentro de la esfera pública: 1) la del "Cuerpo Social", y 2) la "Semántica Inmunitaria". A modo de conclusión en la cuarta sección, sugiero la existencia de una matriz semiótica común y plegada sobre sí misma entre las metáforas de las ciencias biomédicas y sociales, vinculadas al ideario capitalista, colonial y patriarcal que hegemoniza la esfera pública del Norte Global. Buscar una salida a este círculo vicioso es un desafío apremiante para las ciencias críticas y precisa de nuevas formas diálogo en función de acercarse a "otras metáforas" producidas en el Sur Global.

\section{Metáforas, realidad y poder}

Observaba J. L. Borges sobre la función de la metáfora dentro de la poesía: lo importante sería "el hecho de que el lector o el oyente la perciban como metáfora" (BORGES, 2001, p. 37). Al contrario, fuera del ámbito lírico, las metáforas parecen difundirse libremente entre nosotros. Sin reparar demasiado, día a día y frase a frase, utilizamos dentro de nuestras realidades discursivas numerosos sentidos referidos a 
determinados objetos que son trasladados hacia otros objetos diferentes, a través de las metáforas. Lejos de ser artefactos del lenguaje de un orden puramente estilístico o poético (como se planteaba la teoría filosófica clásica), las metáforas serían recursos lingüísticos y cognitivos ampliamente utilizados en un extenso rango de tareas comunicativas, y aún más, pueden ser entendidos como estructuras conceptuales que guían nuestras percepciones y actuar en el mundo.

Así comprende la Teoría Lingüística Cognitiva en uno de sus textos seminales Metaphors we live by, de Lakoff y Johnson (1980). Allí, las metáforas son definidas como: "el entender y experimentar un tipo de cosa en términos de otra", lo cual produciría que ciertas propiedades de los objetos se "iluminen" con la vinculación, al tiempo que quedarán también grandes espacios de "oscuridad" para otras de ellas (LAKOFF; JOHNSON, 1980, p. 13, traducción propia). Para aclarar este punto utilizaré uno de los ejemplos del mismo texto. La frecuente metáfora del tiempo es dinero conllevaría a una serie sistemática de relaciones que vinculan un fenómeno de naturaleza abstracta, altamente subjetiva y culturalmente delimitada como es el tiempo, a "contaminarse" con características de un elemento siempre limitado y dispuesto de transacción, como es el dinero. Sin embargo, esta metáfora aparecería de forma oculta e implícita dentro de frecuentes frases de uso común, como "no gastes mi tiempo", "pierdo mucho tiempo cuando estoy enfermo", "gracias por tu tiempo", "no tengo tiempo para mí", que determinan una visión compartida de sentidos en relación al tiempo, la cual según los autores, estructurarían también la actuación respecto a él. En tanto el tiempo dentro de esta metáfora se vuelve recurso siempre limitado y transable, en tanto el tiempo termina siendo realmente dinero - y la metáfora ya no es más evidente, sino que se fusiona los atributos del uno al otro - hay una visión normativa sobre lo que podemos (o no) hacer con él: la metáfora "muere" dado que se naturaliza y se experimenta como una realidad literal (LAKOFF; JOHNSON, 1980, p. 14).

Como ya se puede intuir, las metáforas habitualmente utilizadas en una sociedad estarán estrechamente vinculadas a su cultura, cosmovisión y escala de valores que las sostienen y se nutren de ellas (LAKOFF; JOHNSON, 1980, p. 23). Así, en las del Norte Global el tiempo de facto es dinero - una visita a cualquier bolsa de valores del capital lo evidencia - y justamente esta concepción guiará los proyectos y las acciones diarias de sus distintos agentes. Esto contrastará radicalmente con otras formas de comprensión sobre el tiempo, regidas por cosmovisiones y escalas 
valóricas diferentes, por ejemplo, en diversas culturas del Sur Global donde el tiempo se relaciona con la circularidad, la recirculación y la permanencia, y por lo tanto, aparecerá como una idea inconmensurable la "pérdida y/o gasto" de él. Por esto Santos (2003) propone que una de las grandes lógicas de creación de noexistencias de la racionalidad occidental-moderna es justamente la "monocultura del tiempo lineal” que sostiene el entramado metafórico capitalista, colonial y patriarcal. Un procedimiento para desmontar esta lógica sería la llamada "ecología de las temporalidades" donde se pretende buscar las diversas reglas y subjetividades sobre el tiempo en las distintas formaciones culturales disponibles en el mundo (SANTOS, 2003, p. 744-748).

Es claro que las metáforas tienen relación con el poder, y para los mismos Lakoff y Johnson (1980) el ejemplo de la metáfora utilizada por el Presidente de los EEUU J. Carter (1977-1981) frente a la crisis energética de su periodo presidencial, es evidente: la de una "guerra moral". Una guerra que invocaba un campo semántico donde emergían enemigos externos, seguridad nacional, blancos a atacar, restricciones y prioridades que antes eran impensada; pero que luego de difundida esta metáfora hacia la esfera pública nacional, comandarán toda una serie de formulaciones políticas y económicas coherentes. Sin embargo al mismo tiempo, refieren los autores, habían otras metáforas para pensar el problema de la crisis energética, otras formas acaso "contrahegemónicas" como los planteamientos de A. Lovins, quien pregonaba por entender que el tipo de energías "duras" versus otras "blandas" es lo que estaba en crisis. La metáfora que se impuso y difundió (y que hasta hoy 2017 sigue vigente) fue la primera, que implicaba al país a una nueva guerra en el medio oriente por petróleo. El poder de enunciación es determinante para la aceptación social de una metáfora emergente dentro de la esfera pública: el presidente de los EEUU "por algo" es el presidente. Aún más, las evaluaciones posteriores respecto al éxito o fracaso de las estrategias de su gobierno siempre tendrán coherencia relativa con la metáfora inicial, de forma que se retroalimentarán mutuamente. En ese sentido el rol de la prensa en la esfera pública - que puede rechazar o aceptar sin mayor cuestionamiento las metáforas que constantemente el poder político de una nación construyen - serían también altamente determinantes en estas dinámicas del poder (LAKOFF; JOHNSON, 1980, p. 117).

La Teoría Lingüística Cognitiva permite entonces reflexionar sobre el apretado ensamblaje entre lenguaje metafórico, cognición, cultura y poder, cuestiones que a 
continuación serán la base para mis análisis sobre dos de las metáforas biomédicas más frecuentes dentro de la esfera pública del Norte Global. La primera, es la sociedad entendida como un cuerpo: la metáfora del Cuerpo Social.

\section{El Cuerpo Social y la terapéutica de la enfermedad social}

George Canguilhem (1904-1995) durante la conferencia traducida como "El problema de las regulaciones en el organismo y la sociedad" dictada el año 1955, se hacía las siguientes preguntas de inicio: “¿Hay algo más que una metáfora en la usual asimilación - unas veces erudita, otras vulgar- de la sociedad a un organismo? ¿Envuelve esta asimilación algún parentesco sustancial?” (CANGUILHEM, 2004, p. 99). Revelando su preocupación por el uso extendido de este traslado de objetos sociales al mundo biológico, y viceversa. Para el autor, sin embargo, no se jugaba en estos "artificios" simplemente la "evolución" de las ciencias, sino que se trataba, ante todo, de una cuestión de resorte político: si la vida social se subordinaba al entendimiento biológico de ella, se abría la puerta a una forma conocimiento que, tarde o temprano, se transformaría en poderosa materia de control y de poder. Esta impronta de carácter utilitarista era la explicaba para Canguilhem la larga supervivencia y uso extendido (en ámbitos académicos y legos) de la metáfora "la sociedad como cuerpo": más que el poder explicativo per se de esta antigua teoría organicista social, su éxito se encontraría en que posibilitaría pensar una intervención del tipo biomédica dentro de una sociedad que "padece de males" imaginados como "enfermedades sociales", y justamente por ello, se entenderán como males curables y corregibles. "Dicho de otro modo, lo que domina la asimilación del organismo a una sociedad es la idea de la medicación social, la idea de la terapéutica social, la idea de remedios para los males sociales" (CANGUILHEM, 2004, p. 103).

En ese orden el autor criticaba la idea de algún tipo de "homeostasis social" sustentada en mecanismos de regulación internos en las sociedades, las cuales posibilitarían la superación de sus sucesivos estados de "crisis". Citando a Cannon, un eminente biólogo de principios del S.XX, este tipo de concepción organicista podría virtualmente explicar cualquier dinámica de conflictos sociales y crisis políticas:

[...] cuando un sistema se mantiene estable, logra hacerlo porque la más pequeńa tendencia a un cambio es atajada de inmediato por el aumento de eficacia del factor o de los factores que se oponen a ese cambio. La tendencia al conservadorismo suscita una rebelión de los elementos de izquierda que, a su vez, es seguida por el retorno al conservadorismo. 
Un gobierno poco severo, con las consecuencias ocasionadas por esta falta de severidad, provoca la llegada al poder de reformadores cuyo rigorismo despertara agitación y el deseo de una mayor libertad (citado en CANGUILHEM, 2004, p. 115).

Evidentemente la utilización de esta figura metafórica aparece algo forzada para el contexto actual, y es que será necesaria la creación y profundización posterior de un nodo conceptual intermedio capaz de vincular de manera más sutil y a la vez más "científica y moralmente neutra" los comportamientos de un organismo único, como el humano, con los del organismo colectivo, como serían par excellence los modernos estados-nación -representando la extensión natural de la comunidad de células y tejidos hacia la comunidad nacional. ${ }^{7}$ Ese nodo conceptual se encontraría en la noción de "norma" o "normalidad".

Ian Hacking en The taming of chance (1990) destaca que en la formación de las incipientes ciencias sociales durante el S.XIX, y en especial en la emergencia de la sociología positivista, el uso de la estadística como forma privilegiada para objetivar y medir los "hechos sociales" se vinculó íntimamente a una noción de "lo normal" en el campo social la cual sería una extensión (traslado y/o importación) directa desde el concepto de "norma" o "normalidad funcional" estudiado por la fisiología médica. Inicialmente importando las ideas del fisiólogo francés Broussais para fundamentar su teoría del "consenso social", habría sido la influyente personalidad de Auguste Comte quien se habría basado en la tesis fisiológica que los estados patológicos eran básicamente desviaciones cuantitativas a partir de una normalidad biológica, donde "the phenomea of disease are of essentially the same kind as those of health, from which they differed only in intensity" (citado en HACKING, 1990, p. 160). Trasladado al campo social, esta "ley fisiológica" hacia un organismo más complejo, un organismo colectivo como el estado-nación moderno, sus principios de funcionamiento (claramente más sofisticados, con instituciones, políticas y revoluciones mediante) debían, sin embargo, seguir básicamente la misma lógica. Así todo un complejo aparato de medición de esta supuesta "normalidad del cuerpo social" fue diseñado para explicar sus múltiples enfermedades, definiendo y perfeccionando una universalidad "natural" de las incipientes leyes sociológicas (HACKING, 1990, p. 160-175).

Así sería Emile Durkheim, quién refinará y realizará un vínculo más sutil y creíble entre el mundo biológico y el social - mediante la utilización de fenómenos de resorte médico entendiéndolos dentro de su contexto social, como en sus análisis 
del suicidio y la criminalidad. Allí, la idea de lo normal y lo patológico biomédico se extenderá hacia el cuerpo social definiendo campos de normalidad dentro de él y grados de desviación que serán observables y medibles mediante sus expresiones sintomáticas ("los hechos sociales"). En el clásico estudio El Suicido (1897) Durkheim se extiende en su metodología y establece un análisis donde - a diferencia de la mayoría del debate en torno a la criminología del periodo - el suicidio y el crimen serán asumidos como partes "normales" de los fenómenos posibles dentro de la sociedad. Lo que representaría una verdadera "desviación” o "estado mórbido", al igual que en la fisiopatología, sería un incremento relativo, o comparativo (en el tiempo o entre sociedades) en las tasas de ocurrencia de ellos (DURKHEIM, 2004).

El problema esencial de esta concepción fisiológica de la sociedad y por lo tanto de la metáfora del "cuerpo social”, es lucidamente revelada por el mismo Canguilhem: dentro de los estados de normalidad de los organismos biológicos, el ser y el ideal del ser, serían esencialmente lo mismo (la vida), es decir, como resultado del mero existir el organismo es su ideal. Cuestión radicalmente distinta a lo que sucede en el funcionamiento social, en la cual los estados de normalidad difieren de los ideales sociales, ergo, no existe claridad respecto al "diagnóstico verdadero" sobre los males sociales que desvían su normalidad, ni tampoco sobre sus causas, consecuencias, ni mucho menos sobre una única fórmula de "terapéutica efectiva" (CANGUILHEM, 2004, p. 99-122). ${ }^{8}$

La metáfora del cuerpo social cae también en descredito dentro del campo de las ciencias sociales del finales del siglo XX a pesar de que en la esfera pública continua manteniendo cierta vigencia. Sin embargo será a partir del desarrollo explosivo de las tecnologías microscópicas y moleculares de la biomedicina, y los eventos políticossociales que se activaron a nivel global a partir de los atentados a las torres gemelas en Nueva York el 11 de septiembre del 2001 que una nueva metáfora parece sostenerse sobre la desgastada imagen del cuerpo social: la Semántica Inmunitaria.

\section{La Semántica Inmunitaria y las fronteras}

W.J.T. Mitchell, en Cloning Terror, hace una interpretación en torno a las imágenes que circularon en la esfera pública a partir de los atentados del 9/11 en los EEUU y sus secuelas posteriores a nivel global. Para el autor, lo relevante del uso analítico de las imágenes mediatizadas, de la "iconología”, sería que dentro de estos medios convergen 
múltiples narrativas sobre la realidad: las imagenes "are both verbal and visual entities, both metaphors and graphic symbols. They are at one and the same time, concepts, objects, pictures, and symbolic forms" (MITCHELL, 2011, p. xvii). Durante esta última década el modo masivo de difusión a nivel mundial de estos dispositivos, y su creciente poder para influir en la conducta humana habrían provocado que además de representar la realidad, estas imágenes tengan la capacidad de crearla. Así, nota Mitchell, no sólo se habría generado una "War on Terror" sino también una espectacular "War of Images" de gran influencia en los contenidos simbólicos a partir del septiembre del World Trade Center y, en especial, a partir de la controvertida respuesta bélica de EEUU que incluyó la emergencia de Osama Bin Laden como figura pública, la invasión de Irak en búsqueda de armas de destrucción masiva inexistentes, y las torturas en nombre de la democracia de Guantánamo; una guerra iconográfica que, por sus formas de diseminación exponencial y “en vivo" a nivel global, adoptaría una poderosa correspondencia con la vida microbiológica bacteriana, y al mismo tiempo, con la rápida respuesta del organismo, el sistema inmunitario:

Images have always possessed a certain infectious, viral carácter, a vitality that makes difficult to contain or quarantine. If images are like viruses or bacteria, this has been a period of breakout, a global plague of images. And like any infectious disease, it has bred a host of antibodies in the form of counterimages (MITCHELL, 2011, p. 2).

Metáfora biológica que se habría vuelto habitual para pensar en las formas de terrorismo y las respuestas de los estados-nación contemporáneas. En la misma corriente discursiva que el renombrado científico del epígrafe de este ensayo, actualmente el terrorismo (por sus inesperadas formas de emergencia, su rápida diseminación, pero principalmente por el uso táctico de las imágenes y símbolos que reproduce utilizando las nuevas tecnologías de información globales) cada vez es más pensado a través de analogías infecciosas: células destructivas, canceres, virus y desordenes autoinmunes, incluso para Mitchell habría una fusión notable: " $a t$ the level of imagery an imagination, all terrorism is bioterrorism, even when it uses traditional forms of violence such as explosives" (MITCHELL, 2011, p. 20).

Incluso el filósofo Jacques Derrida propondrá pensar el terrorismo post 9/11 como una "enfermedad autoinmune", es decir, una condición patológica donde el sistema inmune del organismo erróneamente ataca y destruye células y tejidos propios. La intensión básica de Derrida según Mitchell, habría sido destacar que en el seno del fenómeno terrorista - a diferencia de conflictos armados anteriores 
ligados a un territorio específico y a objetivos militares tradicionales - lo que está en cuestionamiento simbólico es la noción misma de límites, de bordes, de relaciones dentro/fuera del "cuerpo social", de amigos/enemigos, de nativos/extranjeros y, fundamentalmente, de lo que es mera representación (en medios e imágenes) y de lo que es real (la muerte y la tortura). Fusión de lo literal y lo metafórico que se observaría en múltiples formas a través de conductas autoinmunitarias sociales: los estados de excepción y violación de derechos humanos con fines de proteger los mismos, la existencia de una región "a-legal” como la cárcel de Guantánamo, y el simbolismo de un World Trade Center y Bush (como una "cabeza afiebrada" del sistema político-económico mundial) lanzando una paranoica llamada de atención sobre el carácter potencialmente ubicuo del terrorismo yihadista. Este punto admitiría cierta forma de ignorancia e incertidumbre sobre el "real enemigo" terrorista: incubándose dentro del seno de la misma sociedad, en cualquier momento, uno de los "nuestros" puede sufrir una "mutación" y convertirse en elemento antisistémico. Así la respuesta del nuevo cuerpo social deberá ir más allá del análisis político-militar tradicional, para demorarse en el carácter fundamentalmente sanitario de la cuestión: será menester un diagnóstico médico acucioso y un plan de intervenciones acordes, formas de prevención e intervención "smarts", un tipo de "inteligencia inteligente" que simpatice, se infiltre, detenga la amenaza antes incluso de que ocurra (MITCHELL, 2011, p. 45-54).

En ese sentido de refinamiento metafórico parece también hablar R. Esposito en su texto Immunitas, donde destaca la sorprendente congruencia de los mecanismos sociales de exclusión, con la metáfora biológica de los mecanismos inmunitarios. El aparato inmunitario del cuerpo rechaza las células extrañas (no propias) mediante su capacidad de reconocimiento y asimilación del "otro" que permite finalmente la producción de anticuerpos específicos para este. "El veneno es vencido por el organismo no cuando es expulsado fuera de él, sino cuando de algún modo llega a formar parte de este [...] más que a una afirmación, la lógica inmunitaria remite a una no-negación, la negación de la negación” (ESPOSITO, 2009, p. 18). Es evidente que los mecanismos inmunitarios quedan expuestos más claramente en relación a los aparatos jurídicos, y específicamente, cómo ellos intentan eliminar la violencia en la comunidad mediante el uso de violencia "legitimada" o "en dosis adecuadas". Sin embargo, este es sólo el comienzo, y la distinción de lo extraño y lo propio continúan dentro de la aporía que ya estableció Sócrates: o lo extraño es verdaderamente extraño, 
y por ende no accesible, o no lo es, y por ende es ya propio desde el inicio. Para esta segunda tesis, parece ser que el sistema inmunológico denominado "Complejo Mayor de Histocompatibilidad”, como un mecanismo encargado de marcar lo nopropio en el organismo, encuentra un refuerzo, ya que este reconocería lo propio y lo foráneo mediante códigos que ya posee desde el estadio embriogénico que sólo se “recuerdan” con el nuevo contacto con los antígenos (ESPOSITO, 2009, p. 246).

La antigua metáfora del Cuerpo Social es reactualizada, apareciendo un gran y difuso organismo que mal representa un "mundo occidental" enfrentado a "otros mundos" que desconoce - principalmente un gran enemigo, también difusamente visualizado: "el mundo islámico". Allí, se observa con claridad la construcción de la alteridad como un "otro" imaginado desde adentro (o reconocido dentro de un repertorio de códigos predeterminados), y no de alguna nueva movilización de sentidos. Observado desde la Crítica Postcolonial esta semántica estaría estrechamente vinculada a los dispositivos que reproducen las estructuras de dominación y clasificación social contemporáneas, es decir, al capitalismo, al colonialismo y el patriarcado (BHABHA, 2004; FANON, 2009; MBEMBE, 2011; MUDIMBE, 1988; QUIJANO, 2014; SAID, 1978; SANTOS, 2003, 2006; SANTOS; MENESES, 2014; SANTOS et al., 2004; SPIVAK, 1998).

\section{A modo de conclusión: hacia otras metáforas para la comprensión social}

La interpretación que he trabajado durante este articulo parte de la importancia epistémica de las metáforas tanto para las ciencias sociales como para las biomédicas y, de forma inmanente, para la esfera pública del Norte Global. Las dos metáforas en las que profundicé mi análisis, primero en la del Cuerpo Social y luego la Semántica Inmunitaria, representarían una forma de continuidad y refinamiento en virtud de los cambios tecnológicos y socio-políticos históricos. La esfera pública, a su vez, la interpreté como un campo conflictivo donde el dominio de las metáforas (primero puramente narrativas y luego poderosamente visuales) se vuelve cada vez más intenso y de interés global, ya que poseería la capacidad de performar las sucesivas narrativas, los sucesivos mundos donde se reproducirán las futuras experiencias de la realidad dentro de una globalización neoliberal de tendencias altamente homogeneizadoras. Es dentro de este campo de disputa por las metáforas vigentes, 
donde las estructuras del pensamiento biomédico son poderosas, principalmente porque evocan una narrativa de certidumbres basada en la secuencia inamovible de examen/diagnóstico/terapia, la cual proyectada al mundo social, facilita un manejo centralizado y racional del poder, muy acorde con la estructura capitalista/colonial/ patriarcal de los estados-nación del Norte Global. ${ }^{9}$

La vigencia de los discursos en la esfera pública donde se imaginan a los estadosnación como organismos, no habría realmente desaparecido con su desuso dentro del desarrollo de las ciencias sociales a partir del S.XX sino que, como una forma de refinamiento, la metáfora del Cuerpo Social queda oculta, implícita, al movernos (en un zoom) hacia la Semántica Inmunitaria cuya preocupación son los bordes. Interesados ahora por la lógica microscópica de reconocimientos, las actuaciones de seguridad y la legitimidad de las demarcaciones entre lo externo y lo interno, aparece una nueva zona altamente permeable, dinámica y conflictiva del punto de vista socio-cultural, que se vuelve metáfora privilegiada para las ciencias sociales contemporáneas: las fronteras. ${ }^{10}$

No obstante lo anterior, y en confluencia con las dinámicas contradictorias y los discursos propios de la globalización neoliberal contemporánea, con su "nueva gramática” durante las últimas dos décadas, la Semántica Inmunitaria y el análisis de las fronteras parece complicar las cosas, ya que las tradicionales formas de reconocimiento y reacción ante la externalidad son continuamente burladas, y la misma defensa parece actuar de forma contraintuitiva, atacando a sus propios miembros. Así el piso firme de certidumbres parece haberse dañado, y la misma metáfora, aunque superficialmente refinada y coherente, se aprecia cada vez menos defendible dentro de una esfera pública puesta en tensión: la diversidad de sociedades, culturas, instituciones y problemas contemporáneos no son bien comprendidos al pensarnos como meras individualidades biológicas que se defienden constantemente frente a amenazas externas. Dentro de la misma pluralidad interna de las ciencias biológicas hoy se aboga también por nuevos modelos conceptuales donde la interacción entre las especies es central para comprendernos como "sociedades biológicas interdependientes" (p.ej. "holobiontes") con historias evolutivas comunes (GILBERT; SAPP; TAUBER, 2012).

Al profundizar sobre el funcionamiento y las formas de las metáforas biomédicas modernas para explicar el mundo social, se observa una metaestructura conceptual común en su base. Utilizando la misma Semántica Inmunitaria para aclarar este 
punto: se puede pensar que, al igual que en el sistema de reconocimiento de lo propio y lo ajeno del Complejo Mayor de Histocompatibilidad - donde lo que se reconoce como ajeno siempre estuvo dentro del reservorio de reconocimientos posibles, siempre fue "algo propio" - , la matriz semiótica que cruza la comprensión de lo social y lo biomédico del Norte Global se trata básicamente de una sola unidad conceptual anterior, una especie de reservorio finito de metáforas, donde el uso alternado de ellas (en lo social o en lo biomédico) se muestra productivo en el momento que genera una articulación (más o menos estabilizada) con su esfera pública, es decir, cuando logra cierta hegemonía dentro de los discursos del sentido común coyuntural. Siguiendo esta línea, se trataría entonces de mundos en reciprocidad y sinergia; de una matriz acotada y común entre ciencias naturales, ciencias sociales y esfera pública: fragmentos de una ontología fundamentalmente plegada sobre sí misma - donde nada puede imaginarse fuera de sus escalas, normas y sentidos, donde todo es finalmente propio, incluso lo que parece ajeno. ${ }^{11}$

En ese último sentido me parece importante que la Semántica Inmunitaria nos llevaría un límite porque nos enfrenta cara a cara a un callejón sin salida donde la "alteridad radical" es un imposible. Así, esta metáfora representaría una fractura de sentidos en relación a las aspiraciones y acciones de una "nueva esfera pública" (infiltrada por el Sur Global) que, al mismo tiempo que activamente crea formas de comunicación alternativas a las hegemónicas, busca nuevas formas de sanación y re-equilibro en los sistemas curativos de las tradiciones no-occidentales, alcanzando otras metáforas sobre el cuidado, la curación y la vida digna. ${ }^{12}$

Las complejidades biopsicosociales de los procesos de salud y enfermedad actuales, se destaca actualmente desde diversos centros de investigación, requieren de aproximaciones inclusivas apartadas de los modelos modernos cargados de diagnósticos y terapias unívocas y etnocentradas, para abrirse a una pluralidad de voces, saberes y prácticas habitualmente ausentes de estos debates (HERSCH, 2013; HERSCH Y SEDANO, 2013; KRIEGER, 2001; MARTINEZ-ALIER et al., 2014; MENESES, 2004; NUNES, 2014; TROSTLE, 2005).

Si pensamos este doble movimiento a través de la propuesta de Santos (2000) respecto a una nueva "subjetividad de la transición paradigmática" unida íntimamente a nueva epistemología de una "ciencia prudente para una vida decente" (p. 393-396), es posible sostener que dentro de la riqueza de metáforas criadas en el Sur Global - como por ejemplo las que emergen de las experiencias de cuidado/ 
resistencia frente a los embates del extractivismo de la globalización neoliberal en estos territorios - se encuentran políticas ontológicas más capaces de comprender y actuar integralmente ante los problemas que la misma modernidad (el capitalismo, colonialismo y patriarcado) han producido (SANTOS, 2017, p. 172-184).

Posiblemente dentro de este programa abierto a los diálogos interculturales basados en la reciprocidad y el cuidado será posible comprender y sanar las "heridas coloniales persistentes" de las sociedades contemporáneas y sus ecosistemas, orientándonos a mundos futuros de dignidad.

\section{Referencias}

ARBIB, M.; HESSE, M. Language, metaphor, and a new epistemology. In: . The construction of reality. Cambridge: Cambridge University Press, 1986. P. 147-170.

BARILLÉ, A. Érase una ve el Cuerpo Humano. Francia: Savor Ediciones, 1987.

BHABHA, H. K. The Location of Culture. New York: Routlegde, 2004.

BHMBRA, G. K. Rethinking modernity : postcolonialism and the sociological imagination. New York: Palgrave Macmillan, 2007.

BORGES, J. L. La Metáfora. Arte poética. Barcelona: Editorial Crítica, 2001. P. 37-59.

BRADIE, M. Science and Metaphor. Biology and Philosophy, 14, 159-166, 1999.

CANGUILHEM, G. A Vital Rationalist. Selected Writings from Georges Canguilhem (Arthur Goldhammer, Trad.). New York: Zone Books, 2000.

. Escritos sobre la medicina (Irene Agoff, Trad.). Buenos Aires: Amorrortu, 2004.

CITARELLA, L. (comp.). Medicinas y Culturas en la Araucanía. Santiago: Sudamericana, 2000.

CUYUL, A. Salud intercultural y la patrimonialización de la Salud Mapuche en Chile. TA IN FIJKE XIPA RAKIZUAMELUWUN: Historia, colonialismo y resistencia desde el pais Mapuche. Santiago: Ediciones Comunidad de Historia Mapuche, 2012. P. 263-284.

DURKHEIM, E. El suicidio.Estudio de sociología (1897) (Lucila Gibaja, Trad.). Buenos Aires: Losada, 2004.

EFE. Científico explica el cáncer como acto "terrorista" en la "sociedad" del cuerpo. Uruguai, 2011. El Observador. Disponible: <http://www.elobservador.com.uy/cientifico-explica-elcancer-como-acto-terrorista-la-sociedad-del-cuerpo-n32498>. Acceso: 04 feb 2016.

ESPOSITO, R. Immunitas. Protección y negación de la vida. Buenos Aires: Amorrortu, 2009.

FANON, F. Piel Negras, Mascaras Blancas (1952) (Ana Useros, Trad.). Madrid: Ediciones Akal, 2009. 
FOUCAULT, M. El nacimiento de la clínica: una arqueología de la mirada médica (Francisca Perujo, Trad.). México: Siglo XXI, 1966.

GILBERT, S. F.; SAPP, J.; TAUBER, A. I. A Symbiotic View of Life: We Have Never Been Individuals. The Quarterly Review of Biology, v. 87, n. 4, p. 325-341, 2012.

HACKING, I. The taming of chance. Cambridge: Cambridge University Press, 1990.

HARAWAY, D. Simians, Cyborgs and Women. The Reinvention of Nature. New York: Routledge, 1991.

HARDING, S. Introduction. Beyond Postcolonial Theory: Two Undertheorized Perspectives on Science and Technology". In: . (Ed.). The Postcolonial Science and Technology Studies Reader. Durham: Duke University Press, 2011. P. 1-32.

HERSCH, P. Epidemiología sociocultural: una perspectiva necesaria. Salud Pública México, v. 55, n. 5, p. 512-518, 2013.

HERSCH, P.; SEDANO, C. Las comisiones de salud como espacios dialógicos de relevancia para la epidemiología sociocultural. Ejemplos de caso en comunidades de Guerrero y Oaxaca. Oxototitlan. Itinerancias antropológicas, v. 12 (julio-diciembre), p. 5-13, 2013.

IBACACHE-BURGOS, J.; McFALL, S.; QUIDEL, J. Rume Kagenmew Ta Az Mapu. In: CALBUCURA, J. (Ed.). Epidemiología de la Trasgresión en Makewe-Pelale. Nuke Mapuförlaget, 2002.

KELLER, E. F. Making sense of life: Explaining biological development with models, metaphors, and machines. Massashusets: Harvard University Press, 2002.

KRIEGER, N. Theories for social epidemiology in the 21st century: an ecosocial perspective. International Journal of Epidemiology, v. 30, p. 668-677, 2001.

LAKOFF, G.; JOHNSON, M. Metaphors we live by. Chicago: University of Chicago Press, 1980.

LOCK, M. Cultivating the body: Anthropology and Epistemologies of Bodily Practice and Knowledge. Annu. Rev. Anthropol., v. 22, p. 133-155, 1993.

LOCK, M.; NGUYEN, V-K. An Anthropology of Biomedicine. United Kingdom: WileyBlackwell, 2010.

LUPTON D. Body, Medicine and Society. The Social Construcction of Health and Illnes. London: Sage 2010. P. 195-207.

MACHEREY, P. De Canguilhem à Foucault. La force des normes. Paris: La Fabrique Editions, 2009.

MARTIN, E. The Egg and the Sperm: How science has constructed a romance based on stereotypical male-fale roles. Journal of Women in Culture and Society, v. 6, n. 31, p. 485-501, 1991. 
MARTINEZ-ALIER, J. et al. Between activism and science: grassroots concepts for sustainability coined by Environmental Justice Organizations. Journal of Political Ecology, v. 21, p. 19-60, 2014.

MBEMBE, A. Necropolitica seguido de Sobre el Gobierno Privado Indirecto (Elizabeth Falomir Arcaumbault, Trad.). España: Editorial Melusina, 2011.

MENESES, M. P. “Quando não há problemas, estamos de boa saúde, sem azar nem nada": para una concepção emancipatória da saúde e das medicinas. In: SANTOS, B. de S. (Ed.). Semear outras soluçóes: os caminhos da biodiversidade e dos conhecimentos rivais (pp. 357-396). Porto: Afrontamento, 2004. P. 357-396.

MITCHELL, W. J. T. Cloning terror: the war of images, 9/11 to the present. Chicago: The University of Chicago Press, 2011.

MOL, A. Ontologicals politics. A word and some questions. In: LAW, J.; HASSARD, J. (Eds.). Actor Network Theory and After. UK: Blackwell, 1999. p. 74-89.

. The Body Multiple: ontology in medical practice. Durham: Duke University Press, 2002.

MUDIMBE, V.-Y. The Invention of Africa. Gnosis, Philosophy, and the Other of Kwnoledge. USA: Indiana University Press, 1988.

NUNES, J. A. El rescate de la epistemología. In: SANTOS, B. de S.; MENESES, M. P. Epistemologías del Sur. Perspectivas. España: Ediciones Akal, 2014. P. 219-244.

PARKIN, J.; COHEN, B. An overview of the immune system. The Lancet, v. 357, n. 9270, p. 1777-1789, 2001.

QUIJANO, A. Colonialidad del poder y clasificación social (2000). In: SANTOS, B. de S.; MENESES, M. P. Epistemologías del Sur. Perspectivas. España: Ediciones Akal, 2014. p. 67-107.

REYNOLDS, A. S. The deaths of a cell: How language and metaphor influence the science of cell death. Studies in History and Philosophy of Biological and Biomedical Sciences, v. 48, p. 175184, 2014.

ROSEN, G. De la Politica Médica a la Medicina Social. México: Siglo XXI, 1985.

SAID, E. Orientalism. New York: Vintage Books, 1978.

SANTOS, B. de S. A Crítica da razão indolente: contra o desperdício da experiência. Porto: Afrontamento, 2000. . A gramática do tempo. Porto: Afrontamento, 2006.

. A natureza das globalizaçóes. In: . (Ed.). Globalização fa talidade ou utopia? (V. 1). Porto: Afrontamento, 2001. P. 56-76.

. A transição paradigmática: da regulação a emancipação. Oficina do CES, v. 25, p. $1-36,1991$. 
. Epilogue: A New Vision of Europe: Learning from the South. In: BHAMBRA, G. K.; NARAYAN, J. (Eds.). European Cosmopolitanism.Colonial Histories and Postcolonial Societies. London/New York: Routledge, 2017. P. 172-184.

. Para uma sociologia das ausências e uma sociologia das emergências. In: SANTOS, B. de S. (Ed.). Conhecimento prudente para uma vida decente. "Um discurso sobre as Ciências" revisitado. Porto: Afrontamento, 2003. P. 735-775.

Public Sphere and Epistemologies of the South. Africa Development, v. XXXVII, n. 1, p. 43-67, 2012.

Toward a New Common Sense: Law, Science and Politics in the paradigmatic transition. London: Routledge, 1995.

. Um Discurso sobre as Ciências. Porto: Afrontamento, 1987.

SANTOS, B. de S.; MENESES, M. P. Epistemologías del Sur. Perspectivas. España: Ediciones Akal, 2014.

SANTOS, B. de S.; MENESES, M. P.; NUNES, J. A. Introdução: para ampliar o cânone da ciência: a diversidade epistemológica do mundo". In: SANTOS, B. de S. (Ed.), Semear outras soluçóes: os caminhos da biodiversidade e dos conhecimentos rivais. Porto: Afrontamento, 2004. P. 23-106.

SCHEPER-HUGHES, N.; LOCK, M. The Mindful Body: A Prolegomenon to Future Work in Medical Anthropology. Medical Anthropology Quarterly New Series, v. 1, n. 1, p. 6-41, 1987.

SPIVAK, G. ¿Puede hablar el sujeto subalterno? Orbis Tertius, v. III, n. 6, 1998.

TROSTLE, J. Epidemiology and Culture. New York: Cambrige University Press, 2005.

\section{Notas}

${ }^{1}$ Los leucocitos son un tipo de "células móviles" dentro del torrente sanguíneo de gran importancia para el sistema inmunitario del ser humano. También se denominan "glóbulos blancos" debido a que carecen de pigmentación en comparación con los eritrocitos plasmáticos (o glóbulos rojos). En sus diversas formas, los leucocitos tienen por función primordial "defender" al propio organismo "contra" patógenos y "moléculas extranjeras” mediante su reconocimiento, bloqueo o erradicación (PARKIN; COHEN, 2001).

${ }^{2}$ Utilizo esta denominación como lo hace Santos (2003), no en un sentido geográfico, sino en un sentido sociológico, en el cual “...el «Sur» expresa todas las formas de subordinación a los cuales el sistema capitalista dio origen: expropiación, supresión, silenciamiento, diferenciación, desigualdad [...] la forma de sufrimiento humano causado por la modernidad capitalista" (citado en Santos, Meneses y Nunes, 2004, p. 20, traducción mía).

${ }^{3}$ El concepto de esfera pública es utilizado durante este trabajo de forma consciente de su carácter limitado y controversial dentro del Sur Global. Siguiendo la aguda crítica de Santos (2012), se entiende acá que en su base hay una cristalización de valores eurocéntricos (un ideario burgués/moderno/colonial/patriarcal) innecesario para las aspiraciones emancipatorias del Sur Global. No obstante, dentro de este trabajo mi 
análisis justamente se centra en la esfera pública del Norte Global y sus disputas ontológico-discursivas, cuyas consecuencias impactaran en los territorios del Sur Global.

${ }^{4}$ En La dimensión del género una investigación ilustrativa es la de Emily Martin (1991) respecto a la reproducción de estereotipos patriarcales dentro de las explicaciones biomédicas sobre el funcionamiento de óvulos y espermatozoides en la reproducción humana.

${ }^{5}$ Metáforas que Santos $(1995,2000)$ utiliza estratégicamente, por ejemplo, para intentar aprehender prácticas y subjetividades emancipatorias utópicas que se encontrarían fuera de los cánones modernos y posmodernos como lo serían las de "la frontera", "el barroco" y "el Sur".

${ }^{6}$ Para Santos, un localismo globalizado es cierto producto de una cultura local que se globaliza a través de la articulación con diversas fuerzas sociales e instituciones, adquiriendo "la facultad de dictar los términos de integración, competición y de inclusión sobre otros conocimientos rivales” (SANTOS, 2001, p. 71).

${ }^{7}$ Apoyando también, mediante esta semiótica, la construcción de un imaginario histórico-conceptual que oculta el carácter colonial/imperial fundante de los estados-nación modernos, como lo ha destacado en profundidad la critica de Bhambra (2007).

${ }^{8}$ Cabe destacar que parte importante de la obra y legado de Canguilhem tiene que ver la problematización sobre los estados de normalidad y desviación tanto en medicina como en la sociedad (CANGUILHEM, 2000, 2004), los cuales fueron de importante influencia en las elaboraciones de su discípulo Michel Foucault (como intepreta en extensión Macherey, 2009).

${ }_{9}^{9}$ Aunque el ideario neoliberal exalte su descentralización, la geopolítica planetaria continúa concentrando poder y riqueza en las mismas elites vinculadas a los Estados coloniales/imperiales. Las disputas dentro de las esferas públicas de estos países, del Norte Global, serán la que tendrán consecuencias en el Sur, como se ya puede en el momento que escribo luego del Brexit en Reino Unido y la elección de Trump en EUA.

${ }^{10}$ Metáfora usada también precozmente por Santos (1987, p. 396-406) para intentar explorar las dimensiones emancipatorias en términos subjetivos y epistémicos de algunas producciones del Sur Global.

${ }^{11}$ Santos $(1987,2000,2003)$ llamó la atención precozmente sobre esta característica de la ciencia moderna, denominándolo "razón metonímica": una epistemología que se sostiene sobre la certeza de la completitud que homogeniza las diversas partes y produce un diálogo sordo y monocultural.

${ }^{12}$ Lejos de las vertientes de incorporación acrítica de otras tradiciones terapéuticas al Norte Global mediante prácticas del tipo "new age" -que en general adopta posturas altamente individualistas y comerciales, en concordancia con la globalización neoliberal- acá me refiero esencialmente a tradiciones indígenas y subalternas del Sur Global donde la sanación individual sólo es alcanzable mediante acciones comunitarias de cuidado y viceversa -como por ejemplo en el caso de la medicina mapuche (algunas de cuyas caracteristicas se pueden revisar en: Citarella (2000); Cuyul (2012); Ibacache-Burgos et al. (2002). 


\section{Resumo}

Metáforas biomédicas e interpretação social: ausências e emergências na esfera pública contemporânea

$\mathrm{O}$ artigo discute o uso de metáforas biomédicas para interpretar os fenômenos do mundo social contemporâneo. Utilizam-se a Teoria LinguísticaCognitiva e a Crítica Pós-Colonial das Ciências para analisar as metáforas do "Corpo Social" e a "Semântica Imune" da bibliografia selecionada como produtos históricos de transformaçóes tecnológicas e sociopolíticas, cujo caráter é altamente controverso. Este tipo de metáforas evoca uma sequência unilinear de exame/diagnóstico/terapia que socialmente facilitaria uma gestão centralizada e racional do poder. Concluise que Ciências Biomédicas, Ciências Sociais e esfera pública do Norte Global compartilham uma matriz metafórica comum associada com a racionalidade moderna (capitalista /colonial/patriarcal) dobrada sobre si mesma, mas que começa gradualmente a ser fissurada por "outras metáforas" produzidas no Sul global.

Palavras-chave: metáforas biomédicas; epistemologias do Sul; corpo social. 


\section{Abstract}

Biomedical metaphors and social interpretation: absences and emergencies within the contemporary public sphere This paper problematizes the use of biomedical metaphors to interpret the contemporary social world. Using the Cognitive Linguistic Theory and the Postcolonial Studies of Sciences, it analyzes the metaphors of the "Social Body" and the "Immunitarian Semantics" from a selected bibliography as historical products of technological and socio-political transformations of conflicting characteristics. This kind of metaphors evokes a sequence of examination/ diagnosis/social-therapy that facilitates a centralized and rational management of power. Finally, the text suggests that Biomedical Sciences, Social Sciences, and the public sphere of the Global North share a common metaphoric matrix associated with the modern (capitalist/colonial/ patriarchal) rationality, folded over itself, which progressively begins to be fissured by "other metaphors" produced in Global South.

> Keywords: biomedical metaphors; epistemologies of South; social body. 